\title{
New selective medium for isolating Clostridium difficile from faeces
}

\author{
S T Aspinall, D N Hutchinson
}

\begin{abstract}
Aims: To compare CCFA (cycloserine, cefoxitin fructose agar) with a new selective medium CDMN (containing cysteine hydrochloride, norfloxacin, and moxalactam) for the isolation of Clostridium difficile after direct faecal culture.

Methods: The minimum inhibitory concentration (MIC) of norfloxacin was determined for 64 strains of $C$ difficile, 17 strains of other Clostridium sp, and 66 various isolates of faecal origin, together with MIC determinations of moxalactam against the 81 strains of Clostridium sp and 15 isolates of Bacteroides sp. Using $C$ difficile agar base with $0.5 \mathrm{~g} / 1$ of cysteine hydrochloride, norfloxacin and moxalactam were incorporated into the medium and compared with CCFA for the isolation of $\boldsymbol{C}$ difficile after direct faecal culture.

Results: Norfloxacin (12 mg/l) inhibited the growth of enterobacteriaceae and faecal streptococci; moxalactam (32 mg/1) inhibited the growth of most strains of Bacteroides sp tested, together with Clostridium sp other than $C$ difficile. Using the antibiotics in combination (CDMN), the growth and colonial morphology of 64 strains of $C$ difficle were unafiected. When CDMN medium was compared with CCFA for the isolation of $\boldsymbol{C}$ difficile from 832 faeces from inpatients with diarrhoea, the CDMN agar isolated $20 \%$ more strains and reduced the number of contaminating colonies by $30 \%$.

Conclusions: CDMN both improves the isolation rate of $C$ difficile from faecal specimens and reduces the growth of other organisms compared with CCFA.
\end{abstract}

Clostridium difficile is the causal agent of most cases of pseudomembranous colitis ${ }^{1}$ and is frequently linked with many incidents of antibiotic associated diarrhoea. ${ }^{2-4}$ In these instances confirmation that $C$ difficile is the infecting agent is made by detection of the specific cytotoxin or enterotoxin and isolation of the organism. Most laboratories use cycloserine $(500 \mathrm{mg} / \mathrm{l})$, cefoxitin $(16 \mathrm{mg} / \mathrm{l})$ fructose agar (CCFA) for culture, ${ }^{5}$ or the subsequent modification containing half the concentration of antibiotics. ${ }^{6-8}$ Irrespective of antibiotic concentration, the selectivity of the medium is relatively poor and, the use of alcohol shock on the sample before it is plated out is recommended. ${ }^{9}$ The medium also orginally included egg yolk which has more recently been replaced by $7 \%(v / v)$ whole horse blood. This report presents the results of a comparison of CCFA with a new selective medium (CDMN) that uses the same basal agar as CCFA, but incorporates cysteine hydrochloride as a growth supplement, and norfloxacin and moxalactam as selective agents, in the direct culture of faeces for the isolation of $C$ difficile.

\section{Methods}

DETERMINATION OF THE MINIMUM INHIBITORY CONCENTRATION (MIC)

\section{(i) Antibiotics}

Norfloxacin (Merck, Sharp and Dohme Ltd, Hoddeston, England) and moxalactam (Eli Lilly and Co Ltd, Basingstoke, England) were supplied as powders by the manufacturers.

(ii) Micro-organisms

The following organisms were tested: 64 strains of $C$ difficile (including NCTC 11207 and NCTC 11209), three strains of $C$ sordellii (including NCTC 8780), three strains of $C$ bifermentans (including NCTC 6801 and NCTC 6927), three strains of $C$ sporogenes (including NCTC 6929), three strains of $C$ perfringens, one strain of $C$ butyricum, two strains of $C$ septicum, one strain of $C$ tertium, one strain of $C$ novyi, 15 strains of Bacteroides $\mathrm{sp}$, four strains of anaerobic streptococci, 14 strains of faecal streptococci, four strains of Salmonella $\mathrm{sp}$, one strain of Shigella $\mathrm{sp}$, four strains of Yersinia enterocolitica and 24 strains of other enterobacteriaceae.

Isolates (other than NCTC strains) were obtained from clinical specimens. The MIC for each strain was determined against norfloxacin, but against moxalacatam, only isolates of Clostridium sp and Bacteroides sp were examined.

(iii) Media

MICs were performed using two basal media. (a) Clostridium difficile agar base (Unipath Ltd, Basingstoke, England) with $0.5 \mathrm{~g} / 1$ of cysteine hydrochloride (BDH Lab Supplies, Poole, England) and $7 \%(\mathrm{v} / \mathrm{v})$ defibrinated whole horse blood (Lab M Bury, England).

(b) Diagnostic sensitivity test (DST) agar (Unipath Ltd) with $7 \%(\mathrm{v} / \mathrm{v})$ defibrinated whole horse blood (Lab M).

(iv) Method

Freshly prepared $C$ difficile and DST agar containing doubling dilutions of norfloxacin $(4 \mathrm{mg} / 1-512 \mathrm{mg} / \mathrm{l})$ and moxalactam $(0.0625 \mathrm{mg} / 1-256 \mathrm{mg} / \mathrm{l})$ were used for MIC determinations, together with control plates containing no antibiotics. All isolates for testing were incubated overnight aerobically in 
$20 \mathrm{ml}$ volumes of fastidious anaerobe broth (FAB) (Lab M) at $37^{\circ} \mathrm{C}$ before diluting the cultures with fresh FAB until a turbidity was reached roughly equivalent to $10^{6}-10^{7}$ organisms $/ \mathrm{ml}$ (previously assessed). Diluted broths $(20 \mu \mathrm{l})$ were then inoculated on to each of the test media using a Ledwell multipoint applicator (LEEC Ltd, Nottingham, England).

All plates were incubated in an anaerobic atmosphere at $37^{\circ} \mathrm{C}$ for 48 hours.

The MICs of the strains were recorded as the lowest dilution of antibiotic required to inhibit fully growth of the organism. Variation in colonial morphology was also recorded.

STUDY OF FAECAL SPECIMENS

Using a sterile swab, 832 fresh faecal specimens from patients with diarrhoea were directly inoculated on to:

(i) Clostridium difficile base (with $0.5 \mathrm{~g} / 1$ of cysteine hydrochloride and $7 \%$ blood) containing $12 \mathrm{mg} / 1$ of norfloxacin and $32 \mathrm{mg} / 1$ of moxalactam (CDMN).

(ii) Clostridium difficile base with $500 \mathrm{mg} / 1$ of cycloserine and $16 \mathrm{mg} / \mathrm{l}$ of cefoxitin ( $C$ difficile selective supplement, Unipath Ltd) (CCFA).

The plates were then spread four times using a sterile loop and incubated anaerobically at $37^{\circ} \mathrm{C}$ for 48 hours.

All suspect colonies of $C$ difficile were presumptively identified using the $C$ difficile microscreen latex test (Mercia Diagnostics Ltd, Guildford, England) with all positive isolates being confirmed using API ZYM (API bioMèrieux Ltd, Basingstoke, England). ${ }^{1011}$

Growth was assessed semiquantitatively for the isolation of (i) $C$ difficile and (ii) all colonies other than $C$ difficile-contaminants. This was achieved by designating a growth value of between 1 and 5 according to the amount of growth obtained. Growth in the primary inoculation only being given a value of 1 , growth extending into the primary streaks, 2 , growth into the secondary streaks, 3 , and so on up to a growth value of 5 .

\section{Results}

MIC DETERMINATIONS

The MICs of norfloxacin and moxalactam against all isolates tested were similar on $C$ difficile agar base and DST agar base. Table 1 shows the MICs for norfloxacin against 64 strains of $C$ difficile and 83 other bacteria, and

Table 1 MICs of norfloxacin against 64 strains of $C$ difficile and 83 other bacteria, and of moxalactam against 64 strains of $C$ difficile and 36 other anerobic organisms

\begin{tabular}{lcl}
\hline & \multicolumn{1}{l}{$M I C$} & \\
\cline { 2 - 3 } Isolate & $\begin{array}{c}\text { Norfloxacin } \\
\text { (No of strains) }\end{array}$ & $\begin{array}{c}\text { Moxalactam } \\
\text { (No of strains) }\end{array}$ \\
\hline$C$ difficile & $\geqslant 64(63)$ & $\geqslant 128$ \\
$C$ difficile & $32(1)$ & $\mathrm{NT}$ \\
Faecal streptococci & $\leqslant 8(14)$ & $\mathrm{NT}$ \\
Enterobacteriaceae & $\leqslant 4(33)$ & $\leqslant 16(11)$ \\
Bacteroides sp & $\geqslant 32(15)$ & $\leqslant 32(4)$ \\
Bacteroides sp & $\leqslant 8(2)$ & $\leqslant 4(4)$ \\
Anaerobic streptococci & $\geqslant 16(2)$ & \\
Anaerobic streptococci & $\geqslant 16(12)$ & \\
Clostridium sp (other than $C$ difficile) & $\leqslant 8(5)$ & \\
Clostridium sp (other than $C$ difficile) & & \\
\hline NT: Not & &
\end{tabular}

NT: Not tested.
Table 2 Isolation of $C$ difficile and total growth values obtained from 832 faecal specimens

\begin{tabular}{|c|c|c|c|}
\hline \multirow[b]{2}{*}{ Medium } & \multirow{2}{*}{$\begin{array}{l}\text { Total } \\
C \text { difficile } \\
\text { isolations }\end{array}$} & \multicolumn{2}{|c|}{ Growth value } \\
\hline & & $C$ difficile & $\begin{array}{l}\text { Colonies other } \\
\text { than } C \text { difficile }\end{array}$ \\
\hline $\begin{array}{l}\text { CDMN } \\
\text { CCFA }\end{array}$ & $\begin{array}{l}146 \\
122\end{array}$ & $\begin{array}{l}462 \\
408\end{array}$ & $\begin{array}{l}2112 \\
3130\end{array}$ \\
\hline
\end{tabular}

of moxalactam against 64 strains of $C$ difficile and 36 other anaerobic organisms. All isolates of $C$ difficile were resistant to $16 \mathrm{mg} / \mathrm{l}$ of norfloxacin; this concentration inhibited all strains of faecal streptococci and enterobacteriaceae tested. All Bacteroides sp, $50 \%$ of anaerobic streptococci, and most strains of Clostridium sp (other than $C$ difficile) tested were resistant to $16 \mathrm{mg} / \mathrm{l}$ of norfloxacin. The MICs of moxalactam to all 64 isolates of $C$ difficile were $\geqslant 128 \mathrm{mg} / 1 ; 11$ of 15 strains of Bacteroides sp tested, the four strains of anaerobic streptococci, and all 17 strains of Clostridium $\mathrm{sp}$ (other than $C$ difficile) had MICs of $\leqslant 16 \mathrm{mg} / \mathrm{l}$

\section{COLONIAL MORPHOLOGY}

The colonial morphology of the 64 strains of $C$ difficile was identical on the two media, except that beginning with medium containing $16 \mathrm{mg} / \mathrm{l}$ of norfloxacin, an increasing proportion of strains showed a slight reduction in the diameter of the colonies.

STUDY OF FAECAL SPECIMENS

The number of $C$ difficile isolations obtained from 832 faecal specimens, when cultured directly on to both CDMN and CCFA media, together with the total growth values, are shown in table 2. The CDMN agar gave a $20 \%$ higher isolation rate of $C$ difficile than the commercially available CCFA, with the CDMN agar recovering 146 isolates and CCFA recovering 122 . The CDMN agar was also more selective than the commercial CCFA in that it reduced the total growth value of contaminating colonies from 3130 to 2112 (a $33 \%$ reduction), whilst increasing the total growth value of $C$ difficile isolates from 408 to 462 (13\% increase).

\section{Discussion}

Since George and coworkers developed their selective medium in 1979 using cycloserine and cefoxitin (CCFA) no suitable alternative selective agents for the isolation of $C$ difficile from faeces have been commercially available. Using the cycloserine and cefoxitin supplement at the recommended concentration $(500 \mathrm{mg} / \mathrm{l}$ and $16 \mathrm{mg} / \mathrm{l}$, respectively) reports have suggested that it may inhibit some strains of $C$ difficile. To overcome this the supplement has been used at half the concentration but as this reduces the selectivity of CCFA, a form of pretreatment such as alcohol shock has been recommended. ${ }^{8}$ Though reducing the number of contaminants, this also reduces the number of vegetative $C$ difficile organisms, and moreover some laboratories do not wish to add an 
additional stage to their technique. None the less if faeces are cultured directly on to CCFA the selectivity is relatively poor, often allowing a heavy growth of other faecal isolates. Due to the complex nature of faecal bacterial flora and the necessity to select $C$ difficile from other Clostridium sp present, the choice of which antibiotics to use as potential selective agents is a difficult one.

The MICs of numerous antibiotics were determined against a broad range of faecal isolates and strains of $C$ difficile (unpublished data). From these results, norfloxacin and moxalactam were chosen as potential agents. Norfloxacin inhibited all the strains of enterobacteriaceae and faecal streptococci tested at a concentration of $16 \mathrm{mg} / \mathrm{l}$ while maintaining the growth of all $C$ difficile isolates. The norfloxacin was not effective at this concentration against either Bacteroides sp or strains of Clostridium sp (other than $C$ difficile). For this reason, moxalacatam was combined with the norfloxacin at a concentration of $32 \mathrm{mg} / \mathrm{l}$ as this inhibited the growth of all strains of Clostridium sp (other than $C$ difficile) and 11 of 15 strains of Bacteroides sp, without affecting the growth of any of the 64 strains of $C$ difficile tested.

To ensure that neither antibiotic, either alone or in combination, affected the colonial morphology of $C$ difficile, 64 strains were studied. Six isolates were slightly affected at $16 \mathrm{mg} / \mathrm{l}$ of norfloxacin, yet remained unaffected at $12 \mathrm{mg} / \mathrm{l}$. The colonial morphology then remained similar to that on control plates (no antibiotics) when $12 \mathrm{mg} / 1$ of norfloxacin was combined with $32 \mathrm{mg} / \mathrm{l}$ of moxalactam (CDMN) agar. Cysteine hydrochloride $(0.5 \mathrm{~g} / \mathrm{l})$ was also included in the medium as this was not only shown to increase greatly the growth rate of $C$ difficile in brain heart infusion broth (Unipath Ltd), but also significantly to improve the Chatreuse green fluorescence of the colonies under long wave ultraviolet (366 nm) light (unpublished data).

The CDMN medium was $20 \%$ more effective in its isolation rate than in CCFA. The possibility that the 24 additional isolates obtained using the CDMN medium were sensitive to the antibiotics present in the CCFA was investigated by subculturing all 24 strains on to CCFA. All strains grew after 48 hours of anaerobic incubation. One explanation for this is that on primary isolation, the antibiotics present in CCFA were too inhibitory for potentially stressed organisms. On subculture, these were then able to tolerate the antibiotics. The more likely explanation is that the large $(33 \%)$ reduction in the growth of contaminating organisms on the CDMN medium facilitated recognition of lower numbers of $C$ difficile colonies within the faecal culture. This view was supported by the increase in total growth values for isolates of $C$ difficile from 408 to 462 on CDMN medium. The study therefore concludes that $C$ difficile base with $0.5 \mathrm{~g} / 1$ of cysteine hydrochloride, $7 \%$ whole horse blood, $12 \mathrm{mg} / \mathrm{l}$ of norfloxacin and $32 \mathrm{mg} / \mathrm{l}$ of moxalactam is a more sensitive medium supplement for direct culture and isolation of $C$ difficile from faeces than the present commercially available cycloserine cefoxitin fructose agar.

1 George WL, Rolfe RD, Finegold SM. Clostridium difficile and its cytotoxin in faeces of patients with antimicrobial and its cytotoxin in faeces of patients with antimicrobial agent associated diarrhoea and misce

2 George WL, Sutter VL, Finegold SM. Toxigenicity and antimicrobial susceptibility of Clostridium difficile, a cause of anti-microbial agent-associated colitis. Cur Microbiol 1978;1:55-8.

3 Finegold SM. Anaerobic infections and Clostridium difficile colitis emerging during antibacterial therapy. Scand $f$ Infect Dis 1986(Suppl 49):160-4.

4 Lyerly DM, Krivan HC, Wilkins TD. Clostridium difficile: its disease and toxins. Clin Microbiol Rev 1988;1:1-18.

5 George WL, Sutter VL, Citron D, Finegold SM. Selective and differential medium for isolation of Clostridium and differential medium for isolation

6 Willey SH, Bartlett JG. Cultures for Clostridium difficile in stools containing a cytotoxin neutralised by Clostridium stools containing a cytotoxin neutralised by Clostrid
sordellii antitoxin. $f$ Clin Microbiol 1979;10:880-4.

7 Phillips KD, Rogers PA. Rapid detection and presumptive identification of Clostridium difficile by p-cresol production on a selective medium. F Clin Pathol 1981;34 642-4.

8 Levett PN. Effect of antibiotic concentration in a selective medium on the isolation of Clostridium difficile from faecal specimens. $\mathcal{f}$ Clin Pathol 1985;38:233-4.

9 Levett PN. Use of enrichment cultures for the isolation of Clostridium difficile from stools. Microbios Letts 1984;25:67-9.

10 Levett PN. Identification of Clostridium difficile using the API ZYM system. Eur $f$ Clin Microbiol 1985;4:505-7.

11 Head CB, Ratnam S. Comparison of API ZYM system with API AN-Ident, API 20A, Minitek Anaerobe II and RapID-ANA systems for identification of Clostridium difficile. $\mathcal{F}$ Clin Microbiol 1988;26:144-6. 